Байкальский государственный университет, г. Иркутск, Российккая Федерация

Т. А. Туренко

Байкальский государственный университет, г. Иркутск, Российккая Федераиия

\title{
МЕТОДОЛОГИЧЕСКИЕ АСПЕКТЫ ФОРМИРОВАНИЯ КАДРОВ ПРОФЕССИОНАЛЬНЫХ РУКОВОДИТЕЛЕЙ
}

\begin{abstract}
АНнОтАЦия. Современный этап развития экономики выдвигает особые требования к персоналу организации. Особое внимание при этом отводится руководящим кадрам. Ведь именно от их профессионализма во многом зависит эффективность деятельности любой компании. В связи с этим в статье рассматриваются методологические аспекты формирования профессиональных управленческих кадров. Представлена концепция процесса формирования кадров профессиональных руководителей в современных рыночных условиях. Рассмотрены современные внутренние и внешние формы обучения руководителей на основе компетентностного подхода. Описаны методы, используемые в практике обучения руководителей (традиционные, активного и профессионального обучения, коучинг, дистанционное обучение). Обоснована необходимость оценивания изменений, которые произошли с персоналом по истечении времени, на основе профессиональных методов, таких так ассесмент-центр, тестирование по профессиональным компетенциям.
\end{abstract}

кЛючЕВЫЕ словА. Формирование; профессиональные руководители; процесс; законы; закономерности; принципы.

ИНФОРМАЦИЯ О СТАТЬЕ. Дата поступления 11 марта 2016 г.; дата принятия к печати 30 марта 2016 г.; дата онлайн-размещения 31 мая 2016 г.

B. G. Turenko Baikal State University, Irkutsk, Russian Federation

T. A. Turenko

Baikal State University, Irkutsk, Russian Federation

\section{METHODOLOGICAL ASPECTS OF FORMING PERSONNEL OF PROFESSIONAL EXECUTIVE STAFF}

ABSTRACT. The modern stage of economic development puts forward specific demands on the organization's personnel. In this context, special attention is given to the executive staff. After all, it is their professionalism that largely determines the efficiency of any company's performance. In this connection, the article considers $\mathrm{m}$ methodological aspects of forming professional executive staff. It presents a concept of the process of forming personnel of professional leaders in modern market environment. It considers the present-day internal and external forms of training executives on the basis of the competence-based approach. It describes the methods used in practice of training executives (traditional, active and professional training, coaching, distant learning). It substantiates the necessity of assessing the changes which have taken place with the personnel on expiry on the basis of the professional methods such as an assessment center, professional competence testing.

KEYWORDS. Formation, professional executive staff; process, laws; common factors; principles.

ARTICLE INFO. Received March 11, 2016; accepted March 30, 2016; available online May 31, 2016.

(C) Б. Г. Туренко, Т.А. Туренко, 2016

\section{Baikal Research Journal}


В современных условиях развития экономики высококвалифицированные кадры являются важным конкурентным преимуществом любой организации. Компания может повысить свою эффективность, если работники понимают ее миссию, цели развития и стратегию. В связи с этим в научной литературе и публикациях практической направленности большое внимание уделяется проблеме развития персонала.

Каждый из авторов имеет свое видение этой проблемы. Так, И. С. Григорьева считает, что развитие сотрудника в организации - это, прежде всего, развитие его личности, на этой основе формируются профессиональные компетенции, которые так необходимы компании в конкурентной среде бизнеса [1]. Н. Г. Самородская указывает, что развитие сотрудников - это деятельность, включающая систему управленческих технологий, методов и мероприятий, направленных на совершенствование профессионального, личностного потенциала персонала, его социально-психологических компетенций, лидерских качеств с целью повышения эффективности работы компании и повышения личной эффективности. Развитие персонала ориентировано на будущее и взаимосвязано со стратегией развития компании в целом [2]. В. М. Маслова понимает профессиональное развитие как процесс подготовки сотрудников к выполнению новых производственных функций, занятию новых должностей [3].

Особое значение развитие персонала имеет для управленческих кадров. В связи с этим считаем необходимым остановиться на проблеме формирования кадров профессиональных руководителей. Если вопросы подбора, расстановки, подготовки кадров довольно подробно рассмотрены в соответствующей научной литературе [4-9], то формирование профессиональных кадров управления, оценка их деловых и личностных качеств на данный момент являются недостаточно изученными как в теоретическом, так и в методологическом плане.

Эффективность функционирования организации в значительной мере зависит от профессиональной подготовки кадров управления. Сейчас является уже бесспорной необходимость обучения современного руководителя науке управления и практике руководства. Ведь как утверждает М. В. Топлаканян, профессиональные руководители используют новые методы работы, помнят о важности обратной связи, в курсе всех новшеств на профессиональном рынке, изучают последнюю информацию. Они придерживаются гибкого подхода к построению системы управления, стремятся превратить компанию в структуру, чутко реагирующую на запросы потребителей [10].

На основании проведенного ранее исследования [11] мы можем утверждать, что профессиональный руководитель - это специалист управления, занимающий руководящую должность и осуществляющий руководство персоналом. Далее остановимся на методологических аспектах процесса формирования профессиональных руководителей.

Формирование кадров управления является сложным многогранным процессом, требующим научного управления его развитием, и должно осуществляться на основе учета действия законов, закономерностей и использования принципов управления. Процесс формирования управленческих кадров, как и любой вид человеческой деятельности, развивается согласно объективным закономерностям, выражающим определенные специфические отношения, характерные для этой деятельности и являющиеся результатом действия более общих законов и закономерностей, определяющих его развитие - закона неуклонного роста производительности труда, закона соответствия производственных отношений характеру и уровню развития производительных сил, закона стоимости, закона единства и борьбы противоположностей, закона отрицания отрицания, закона перехода количественного изменения в качественное и др.

\section{Baikal Research Journal}

электронный научный журнал Байкальского государственного университета 
Результатом действия и взаимодействия законов диалектики и законов функционирования социально-экономической системы, а также закономерностей управления в области отношений по формированию управленческих кадров является закономерность единства обучения и практики управления. Она имеет все основные признаки закономерности:

- выражает существенные связи, основные внутренние цепочки явлений обучения и практики управления (это подтверждается определением сущности понятия знания, как научной категории: в философии знание трактуется как суть, проверенная практикой, результат познания действительности, ее отражение в сознании человека);

- представляет собой устойчивые связи обучения и практики, что подтверждает история обучения управленческих кадров в России;

- выражает общую связь явлений в области формирования кадров управления и охватывает не одно, а сравнительно большую группу однородных явлений: формирование квалифицированных специалистов, руководителей и т. д.

Все эти признаки, вместе взятые, характеризуют данную закономерность как научную категорию. Поскольку зависимость формирования управленческих кадров от процессов и явлений, происходящих в практике управления предприятием, выражает существенные, устойчивые, общие, необходимые и повторяющиеся связи, постольку она может классифицироваться как важнейшая закономерность формирования управленческих кадров, определяющая единство обучения и практики управления.

В результате действия основных законов диалектики - единства и борьбы противоположностей, отрицания отрицания, перехода количественного изменения в качественное - в сфере отношений по формированию кадров управления возникает еще ряд закономерностей процесса формирования управленческих кадров, обладающих общими признаками закономерностей. Так, результатом действия закона единства и борьбы противоположностей является закономерность сохранения (гомеостазиса) и развития, определяющая необходимость сохранения и одновременно развития организационных форм процесса формирования кадров управления. А закономерность соответствия организационной структуры системы подготовки, переподготовки и повышения квалификации кадров управления величине и структуре материального и информационного потоков, проходящих через эту систему, является результатом действия закона перехода количественных изменений в новое качество. Она обуславливает объективную необходимость быстрого изменения структуры организационных форм системы подготовки кадров управления при достижении потоков определенного уровня, так как всякое внешнее воздействие обязательно должно преобразовывать внутреннюю структуру системы, стремящейся к стабильности функционирования. Закон отрицания отрицания порождает закономерность непрерывного развития процесса формирования кадров управления по $S$-образным кривым. Данная закономерность определяет объективность трех этапов: это начало, развитие и спад выпуска специалистов соответствующей квалификации. Поэтому для эффективной работы организационных форм системы подготовки, переподготовки и повышения квалификации кадров управления необходимы подготовка и выпуск таких специалистов, которые были бы постоянно востребованы рынком.

Одновременное воздействие трех основных законов диалектики порождает в сфере рассматриваемых отношений закономерность реальности формирования профессионального специалиста. В соответствии с требованиями этой закономерности формирование профессионального специалиста должно осуществляться на основе спирали восхождения специалиста, так как она отражает действие трех законов диалектики: единства и борьбы противоположностей (теории и практики); отрицания отрицания (низшая, средняя, высшая квалификации специалиста) и переход коли-

\section{Baikal Research Journal}

электронный научный журнал Байкальского государственного университета 
чества в новое качество (специалист низового уровня управления системы, среднего уровня и высшего уровня). Эта закономерность может быть представлена в виде спирали формирования специалиста, отражающей все основные законы диалектики. Формирование специалиста от низового уровня управления системы к более высокому уровню является диалектической формой его развития. По этой спирали специалист сознательно должен подниматься наверх, на качественно более высокий уровень управления системы, выполняя требования названной закономерности.

Указанные ранее закономерности, раскрывая сущность и природу явления формирования кадров управления, являются необходимой ступенью к всестороннему познанию многообразной практики формирования управленческих кадров. Таким образом, формирование кадров управления представляет собой процесс создания профессиональных руководителей и специалистов на основе прохождения соответствующей управленческой подготовки, оценки и практики управления для приобретения знаний, умений и навыков, формирующих их основные профессиональные качества.

Из этого вывода просматривается непосредственная связь процесса формирования профессиональных руководителей с компетентностным подходом к их обучению. Известно, что профессиональная компетенция - это способность успешно действовать на основе практического опыта, умений и знаний при решении профессиональных задач. Для формирования профессиональных компетенций могут применяться три основных вида обучения: подготовка, повышение квалификации и переподготовка кадров [3].

Следует различать внутренние и внешние формы обучения персонала. Из-за относительно высокой стоимости внешнего обучения российские компании широко используют обучение вне организации для руководителей высшего и среднего звена или резерва.

В настоящее время наряду с традиционными формами используется модульное, дистанционное и мультимедийное обучение [12].

В практике обучения руководителей применяют различные методы:

- традиционные - лекции, семинары, видеообучение;

- активного обучения - тренинги, групповые обсуждения, деловые и ролевые игры, поведенческое моделирование, разбор практических ситуаций, баскет-метод;

- профессионального обучения - производственный инструктаж, наставничество, стажировки, ротация кадров, использование работников в качестве ассистентов, подготовка в проектных группах.

Одним из сравнительно новых направлений обучения является коучинг — форма консультирования, ориентированная на прояснение клиентом собственных целей и успешного достижения их за счет внутренних ресурсов и источников мотивации. Многие организации используют в настоящее время дистанционное обучение - способ реализации процесса обучения, основанный на использовании современных информационных и телекоммуникационных технологий, позволяющих осуществлять обучение на расстоянии без непосредственного контакта между преподавателем и обучающимся [12]. Таким образом, в современных условиях существует множество возможностей для эффективного осуществления такого элемента формирования кадров профессиональных руководителей, как управленческая подготовка.

Особое место в процессе формирование кадров управления занимает оценка развития персонала. При оценке развития персонала следует по заданным критериям оценить изменения, которые произошли с персоналом по истечении времени, т. е. определить, появились ли у сотрудников новые качества, умения, навыки. Оценка развития должна происходить в динамике. Для оценки можно использовать профессиональные методы, такие так ассесмент-центр, тестирование по профессиональным компетенциям.

\section{Baikal Research Journal}

электронный научный журнал Байкальского государственного университета 
Ассесмент-центр - метод, который зарекомендовал себя как надежный и валидный, особенно для руководящих должностей или при оценке возможных ротаций. Огромным достоинством этого метода является то, что он имеет высокую прогностическую валидность, т. е. позволяет составить прогноз дальнейшего поведения сотрудника, в том числе в аспекте его развития. Тестирование по профессиональным компетенциям - это комплекс тестов по узким специальным знаниям или навыкам в профессии, например, тесты для финансовых директоров, бизнес-аналитиков, маркетологов, производственных специалистов. Такие тесты создают на заказ экспертные сообщества (союзы аудиторов, общества оценщиков и т. д.), и объективность их достаточна.

При оценке развития управленческих навыков и компетенций необходимо обратить внимание на следующее: развитие навыков по управлению собой дает возможность развить навыки управления людьми. Умение управлять собой и строить свой жизненный путь надлежит оценивать как потенциал прогрессивного развития корпоративных управленческих навыков. Иными словами, человек, умеющий ставить перед собой цели, осуществлять долгосрочное и краткосрочное планирование, оценивать риски и выгоды, контролировать достижение собственных целей и корректировать свои действия, имеющий внутреннюю мотивацию на реализацию целей и задач и берущий ответственность за все свои успехи и неудачи при достижении целей, уже имеет базовый потенциал для развития управленческих компетенций [1].

Таким образом, формирование кадров профессиональных руководителей является сложной и важной проблемой, которая стоит перед любой организацией, стремящейся к успешной и эффективной деятельности.

\section{Список использованной литературы}

1. Григорьева И. С. Как оценить развитие персонала в организации / И. С. Григорьева // Управление развитием персонала. - 2015. - № 4 (44). - С. 246-251.

2. Самородская Н. Г. Критерии оценки эффективности развития сотрудников / Н. Г. Самородская // Управление развитием персонала. - 2015. - № 4 (44). - С. 258-266.

3. Маслова В. М. Управление персоналом / В. М. Маслова. - М. : Юрайт, 2013. - 492 с.

4. Егоршин А. П. Управление персоналом / А. П. Егоршин. - М. : Инфра-М, 2010. - 520 с.

5. Шекшня С. В. Управление персоналом современной организации / С. В. Шекшня. М. : Бизнес-школа «Интел-Синтез», 2012. - 355 с.

6. Развитие российского общества: социально-экономические и правовые исследования / О. В. Батурина [и др.] ; под ред. М. А. Винокурова, А. П. Киреенко, С. В. Чупрова. - М. : Наука, 2014. - $622 \mathrm{c}$.

7. Иркутская область в XXI веке: проблемы и ресурсы развития / А. П. Киреенко, С. В. Чупров, Л. В. Санина [и др.]. - Иркутск : Изд-во БГУЭП, 2014. - 422 с.

8. Сфера социально значимых услуг: теоретические и прикладные аспекты деятельности организаций : в 2 ч. / под общ. ред. Т. Д. Бурменко, О. Н. Баевой. - Иркутск : Изд-во БГУЭП, 2012. - Ч. 1. - 380 с.

9. Институциональные изменения в сфере социально значимых услуг / Т. Д. Бурменко, В. Ю. Баганов, О. Н. Баева ; отв. ред. Т. А. Кондрацкая. - Иркутск : Изд-во БГУЭП, 2013. $268 \mathrm{c}$.

10. Топлаканян М. В. Топ-менеджер в современных экономических условиях / М. В. Топлаканян // Менеджмент сегодня. - 2012. - № 1 (67). - С. 44-49.

11. Туренко Б. Г. Комплексная стратегия развития предприятий малого и среднего бизнеса / Б. Г. Туренко, Т. А. Туренко. - Иркутск : Изд-во БГУЭП, 2013. - 224 с.

12. Управление персоналом / под ред. А. А. Литвинюка. - М. : Юрайт, 2012. - 434 c.

\section{References}

1. Grigoryeva I. S. How to assess personnel development in a company. Upravlenie razvitiem personala = Personnel Development Management, 2015, no. 4 (44), pp. 246-251. (In Russian).

\section{Baikal Research Journal}


2. Samorodskaya N. G. Criteria of assessing efficiency of personnel development. Upravlenie razvitiem personala $=$ Personnel Development Management, 2015, no. 4 (44), pp. 258-266. (In Russian).

3. Maslova V. M. Upravlenie personalom [Personnel management]. Moscow, Yurait Publ., 2013. $492 \mathrm{p}$.

4. Egorshin A. P. Upravlenie personalom [Personnel management]. Moscow, Infra-M Publ., 2010. $520 \mathrm{p}$.

5. Shekshnya S. V. Upravlenie personalom sovremennoi organizatsii [Personnel management in a present-day company]. Moscow, Intel-Sintez Publ., 2012. $355 \mathrm{p}$.

6. Baturina O. V. et al. Vinokurov M. A., Kireyenko A. P., Chuprov S. V. (eds). Razvitie rossiiskogo obshchestva: sotsial'no-ekonomicheskie i pravovye issledovaniya [Russian Society Development: Socio-Economic and Legal Research]. Moscow, Nauka Publ., 2014. 622 p.

7. Kireyenko A. P., Chuprov S. V., Sanina L. V. et al. Irkutskaya oblast' $v$ XXI veke: problemy $i$ resursy razvitiya [Irkutsk Oblast in the 21st Century: Problems and Development Resources]. Irkutsk, Baikal State University of Economics and Law Publ., 2014. $422 \mathrm{p}$.

8. Burmenko T. D., Bayeva O. N. (eds). Sfera sotsialno znachimykh uslug: teoreticheskie $i$ prikladnye aspekty deyatelnosti organizatsii [Scope of Socially Important Services: Theoretical and Applied Aspects of Companies' Activities]. Irkutsk, Baikal State University of Economics and Law Publ., 2012. Pt. 1. 380 p.

9. Burmenko T. D., Baganov V. Yu., Bayeva O. N. et al.; Kondratskaya T. A. (ed.). Institutsional'nye izmeneniya $v$ sfere sotsial'no znachimykh uslug [Institutional Changes in the Sphere of Socially Significant Services]. Irkutsk, Baikal State University of Economics and Law Publ., 2013. $268 \mathrm{p}$.

10. Toplakanyan M. V. Top manager in present-day economic environment. Menedzhment segodnya = Management Today, 2012, no. 1 (67), pp. 44-49. (In Russian).

11. Turenko B. G., Turenko T. A. Kompleksnaya strategiya razvitiya predpriyatii malogo $i$ srednego biznesa [Comprehensive Strategy of Small and Medium-Sized Business Development]. Irkutsk, Baikal State University of Economics and Law Publ., 2013. 224 p.

12. Litvinyuk A. A. (ed.). Upravlenie personalom [Personnel management]. Moscow, Yurait Publ., 2012. 434 p.

\section{Информация об авторах}

Туренко Борис Григорьевич - доктор экономических наук, профессор, кафедра экономики и управления бизнесом, Байкальский государственный университет, 664003, г. Иркутск, ул. Ленина, 11, e-mail: tturenko@rambler.ru.

Туренко Татьяна Александровна - кандидат экономических наук, доцент, кафедра менеджмента, маркетинга и сервиса, Байкальский государственный университет, 664003, г. Иркутск, ул. Ленина, 11, e-mail: tturenko@rambler.ru.

\section{Authors}

Boris G. Turenko - Doctor habil. (Economics), Professor, Chair of Business Economics and Management, Baikal State University, 11 Lenin St., 664003, Irkutsk, Russian Federation; e-mail: tturenko@rambler.ru.

Tatyana A. Turenko - PhD in Economics, Associate Professor, Chair of Management, Marketing and Services, Baikal State University, 11 Lenin St., 664003, Irkutsk, Russian Federation; e-mail: tturenko@rambler.ru.

\section{Библиографическое описание статьи}

Туренко Б. Г. Методологические аспекты формирования кадров профессиональных руководителей / Б. Г. Туренко, Т. А. Туренко // Baikal Research Journal. — 2016. — Т. 7, № 3. DOI : $10.17150 / 2411-6262.2016 .7(3) .17$.

\section{Reference to article}

Turenko B. G., Turenko T. A. Methodological aspects of forming personnel of professional executive staff. Baikal Research Journal, 2016, vol. 7, no. 3. DOI : 10.17150/24116262.2016.7(3).17. (In Russian).

\section{Baikal Research Journal}

